\title{
A necessidade da oferta de formação superior multicultural a distância pelo Instituto Insikiran da Universidade Federal de Roraima
}

\author{
La necesidad de la provisión de educación superior multicultural a \\ distancia por parte del Instituto Insikiran de la Universidad Federal de
}

Roraima

\author{
The need for the provision of distance multicultural higher education by \\ the Insikiran Institute of the Federal University of Roraima
}

Paulo Fernando de Lucena Borges Ferreira ${ }^{1}$

\begin{abstract}
Resumo
Esse estudo tem por finalidade compreender novas perspectivas multiculturais linguísticas relacionadas à necessidade de um Curso de Formação Superior em Língua Macuxi na Modalidade a distância que pode ser ofertado pelo Instituto de Formação Superior Indígena Insikiran da UFRR. No interesse de cumprir esse propósito, o aprofundamento teórico se fundamentou e base bibliográfica como Bakhtin (1992), Bobbio (1992), Meliá (1999), McLaren (2000), Canclini (2004), Manzini (2006), Cavalcanti e César 2007, Carvalho, Fernandes e Repetto (2009), Baniwa (2010). Após esse momento qualitativo, em trabalho de campo, foram entrevistados dois professores que atuam no Programa de Valorização das Línguas e Cultruras Macuxi e Wapichana, da UFRR. Todos os participantes se submeteram ao TCLA que fora lido de maneira oral por meio de aplicativo de Rede Social WhatsApp, sendo demonstrada de maneira verbalizada a participação voluntária e sem ônus destes participantes. Seguindo aos trabalhos de campo, foram entrevistados por meio de questionário com oito perguntas abertas, 30 alunos do curso de Gestão em Saúde Coletiva do Instituto Insikiran. Com ajuda desses recursos, modelos e instrumentos metodológicos se pôde compreender o interesse e viabilidade de um curso Curso de Formação Superior em Língua Macuxi na Modalidade a distância que pode ser ofertado pelo Instituto de Formação Superior Indígena Insikiran da UFRR.
\end{abstract}

Palavras-chave: Formação Superior; Multiculturalismo; Línguas Indígenas.

\section{Resumen}

Este estudio tiene como objetivo comprender las nuevas perspectivas lingüísticas multiculturales relacionadas con la necesidad de un curso de educación superior Macuxi de educación a distancia que pueda ofrecer el Instituto de Educación Superior Indígena Insikiran de la UFRR. En aras de cumplir con este propósito, la profundización teórica se basó y la base bibliográfica como Bakhtin (1992), Bobbio (1992), Meliá (1999), McLaren (2000), Canclini (2004), Manzini (2006), Cavalcanti y César 2007, Carvalho, Fernandes y Repetto (2009), Baniwa (2010). Después de este momento cualitativo, en el trabajo de campo, se entrevistó a dos maestros que trabajan en el Programa de Apreciación de Lengua y Cultura Macuxi y Wapichana de la UFRR. Todos los participantes se presentaron al TCLA, que había sido leído oralmente a través de la aplicación WhatsApp Social Networking, demostrando la participación voluntaria y gratuita de estos participantes. Después del trabajo de campo, se entrevistó a 21 estudiantes del curso de Gestión de Salud Colectiva del Instituto Insikiran utilizando ocho preguntas abiertas. Con la ayuda de estos recursos, modelos y herramientas metodológicas, fue posible comprender el interés y la viabilidad de un curso de educación a distancia en

\footnotetext{
${ }^{1}$ Programa de Pós-graduação em nível de mestrado em Letras da Universidade Federal de Roraima PPGL/UFRR. E-mail: prof.lucenaferreira@gmail.com.
} 
Educación Superior en Lengua Macuxi que puede ofrecer el Instituto de Educación Superior Indígena de la UFRR.

Palabras clave: Educación superior; Multiculturalismo; Lenguas indígenas

\begin{abstract}
This study aims to understand new linguistic multicultural perspectives related to the need for a Distance Learning Macuxi Higher Education Course that can be offered by the Institute of Indigenous Higher Education Insikiran of UFRR. In the interest of fulfilling this purpose, the theoretical deepening was based and bibliographic base as Bakhtin (1992), Bobbio (1992), Meliá (1999), McLaren (2000), Canclini (2004), Manzini (2006), Cavalcanti and César 2007, Carvalho, Fernandes and Repetto (2009), Baniwa (2010). After this qualitative moment, in the field work, two teachers who work in the UFRR's Macuxi and Wapichana Language and Culture Appreciation Program were interviewed. All participants submitted to the TCLA, which had been read orally through the WhatsApp Social Networking application, demonstrating the voluntary and free participation of these participants. Following the fieldwork, 21 students from the Insikiran Institute's Collective Health Management course were interviewed using eight open-ended questions. With the help of these resources, models and methodological tools, it was possible to understand the interest and feasibility of a distance learning course in Macuxi Language Higher Education that can be offered by the Institute of Indigenous Higher Education of UFRR.
\end{abstract}

Keywords: Higher Education; Multiculturalism; Indigenous languages.

\title{
1. Introdução
}

Este estudo trata-se de conteúdo ainda em andamento, que comporá a Dissertação intitulada: "Demandas e Possibilidades de um Curso de Língua Macuxi a Distância na Universidade Federal de Roraima".

Neste contexto, este trabalho se fundamentou em compreender a Formação Superior Indígena Multicultural e a necessidade de se considerar a criação de um Curso superior de Língua Macuxi que possa ser disponibilizado diretamente nas comunidades locais de origem (e não apenas na capital), assumindo, assim, um novo posicionamento da formação acadêmica e exercício cidadão de emancipação dos indivíduos que compõem esses núcleos sociais que são histórica e culturalmente diversificados.

Visando cumprir essa finalidade, por meio de perfil bibliográfico qualitativo de pesquisa, a sistematização do tema relacionou-se os objetivos propostos com bibliografia que ampliasse uma melhor reflexão sobre este assunto. Dessa forma essa teoria se fundamentou em estudos de Baniwa (2010), Bobbio (1992), Canclini (2004), Cavalcanti e César (2007), Fernandes (2008), Freitas (2003) e Meliá (1999), Maher (2007), McLAREN (2000), possibilitando uma melhor discussão sobre a ótica de estudo.

$\mathrm{Na}$ análise, a temática se fundamentou teoricamente com declarações da professora Machado (2018) do Programa de Pós-graduação em nível de mestrado PPGL/UFRR e do Professor de Língua Macuxi, Mafra (2018), ambos atuam também no Programa de 
Valorização das Línguas e Cultruras Macuxi e Wapichana. Também foram entrevistados 21 alunos do Curso de Gestão em Saúde, no intuito de aprofundar os objetivos da pesquisa.

Compreender como a Formação Superior indígena multicultural pode servir como um elemento que considere demandas de Formação Superior em Língua Indígena em Roraima, visto que não existem ainda graduações com este teor, tendo somente sido disponibilizados cursos de extensão acadêmica por professores falantes de línguas indígenas locais. Proporcionar uma graduação que supere obstáculos para a formação de profissionais nesta Língua Indígena serviria como uma oportunidade de motivar uma melhor reflexão sobre o direito dos povos que formam essa identidade local diversificada.

\title{
2. A formação pedagógica intercultural no Brasil
}

Os primeiros estudos sobre Formação Superior Indígena, no Brasil, estão presentes nos estudos de Meliá, ${ }^{2}$ na década de 1970 . Com relação à educação e à formação pedagógica voltada aos indígenas, Meliá (1999), destaca:

\begin{abstract}
A ação pedagógica tradicional integra sobretudo três círculos relacionados entre si: a língua, a economia e o parentesco. São os círculos de toda cultura integrada. De todos eles, porém, a língua é o mais amplo e complexo. O modo como se vive esse sistema de relações caracteriza cada um dos povos indígenas. $\mathrm{O}$ modo como se transmite para seus membros, especialmente para os mais jovens, isso é a ação pedagógica (MELIÁ 1999, p. 03).
\end{abstract}

Carvalho; Fernandes e Repetto (2009) destacam que diferentes culturas geram diferentes fonte de conhecimento que poderiam superar limites da razão, servindo como fontes de interação entre diferentes povos e diferentes indivíduos de maneira ampla e diversificada:

Poderíamos considerar a ciência como uma cultura do conhecimento que faz parte da cultura em sentido amplo. Assim entendemos que a ciência entendemos que a ciência é apenas parte do real, e por isso pode ser segmentada em disciplinas e áreas de conhecimento, o que nos obriga a buscar diálogos inter e transdisciplinares.

\footnotetext{
2 Bartomeu Meliá Llitere é um jesuíta, antropólogo e um brilhante etnolinguísta espanhol. Radicou-se no Paraguai em 1954, onde iniciou seus estudos da língua e da cultura guarani. Doutor em Ciências Religiosas pela Universidade de Estrasburgo (Francia), ex-professor de Etnologia e Cultura Guarani da Universidade Católica de Assunção e presidente do Centro de Estudos Antropológicos desta mesma universidade. Professor convidado na USP - São Paulo. Doutor em Ciências Religiosas (Universidade de Estrasburgo), professor na Universidade Católica de Assunção. Diretor do Centro de Estudios Paraguayos “Antonio Guasch". Disponível em: <http://www.nhanduti.com/Catalogo/Pasado,\%20presente,\%20Futuro.\%20Guarani/Bartomeu\%20Melia.Biografi a1.html>. Acesso em 28 de jun. de 2018.
} 
Enquanto a cultura é uma realidade completa e auto-construída a partir do diálogo com outras culturas, que expressa uma visão do mundo, é um olhar sobre a totalidade do real, do todo, embora sempre o veja em parte. As culturas são fontes de conhecimento e auto-compreensão que superam os limites da razão, e nos levam a pensar nos limites do Ser (CARVALHO; FERNANDES; REPETTO, 2009, p. 101).

A cultura, conforme o destacado por Carvalho; Fernandes e Repetto (2009) fundamenta-se na celebração do conhecimento em suas relações de diálogo social e constante, multifacetando contextos e celebrando encontros de diferenciadas possibilidades de interação sociocultural, o que diretamente, amplifica o sentido e entendimento da visão de mundo.

Tubino (2003) entende que o multicuturalismo contribuiu para gerar tolerância e equidade cultural, sendo que de mesmo modo gerou também ilhas étnicas, sociedades paralelas, o que, de algum modo, fomentou um outro modo de etnocentrismo vez que, por vezes um grupo cultural, não consegue estabelecer trocas culturais efetivas com outro grupo, havendo novas demandas de superem concepções equivocadas que hajam relações de maior importância entre uma cultura e outra.

Assim, esse novo modo de compreender a cidadania intercultural se posiciona no entendimento de que os "povos indígenas existem muito antes da concepção ou criação do Estado" e, partindo deste entendimento, essa compreensão deve motivar o resguardado das diferentes realidades e perspectivas de sua identidade cultural, legitimando suas demandas de direito no Estado (TUBINO, 2003, p.182).

Para tanto, nesse processo de reconhecimento e resguardo de identidade cultural diversificada, também se verifica a necessidade de uma formação acadêmica que se adeque aos contextos presentes nessa "formação cultural diferenciada dos povos indígenas", como a exemplo dos presentes no Estado de Roraima. Esse novo perfil acadêmico encontra seu reflexo também nos elementos que construirão novos perfis profissionais que se adequem a diferentes realidades fluídas embasadas em amplas visões de mundo (GOMES; SILVA, 2006, p.15).

Repetto (2008) destaca que a defesa fundamental da cidadania intercultural deve absorver em seu conceito a concretização de uma sociedade, onde a cidadania deixe de ser um conceito abstrato e homogeneizante, para gerar uma sociedade que respeite o direito das pessoas individualmente, bem como o direito das coletividades.

Visando atender a essa demanda atual por uma formação acadêmica multiculturalizada, o Instituto Insikiran da Universidade Federal de Roraima - UFRR tem contribuído para a formação de profissionais eficientes e que se adequem às necessidades da comunidade local dando todo o suporte necessário para que estes alunos possam atuar de 
maneira significativa e eficiente. Essa formação diferenciada tem possibilitado o exercício de uma cidadania intercultural que englobe direitos e liberdades já reconhecidos em demandas internacionais como o direito à vida, a livre determinação dos povos, à justiça, à liberdade, igualdade de tratamento e tutela diante da lei, liberdade de expressão, informação, direitos relativos às minorias étnicas, religiosas e linguísticas bem como e ao exercício e reconhecimento de sua própria cultura (BOBBIO, 1992).

Este processo pode viabilizar uma nova visão dos diferentes processos culturais formativos dos povos indígenas, visto que no decurso da história tem sido deixado de lado pelos indígenas mais jovens que buscam os grandes centros urbanos para viverem e conduzirem suas vidas, esquecendo-se de como foram construídas suas culturas, as conquistas e perseguições que seus povos sofreram e ainda assim, persistem na defesa da paz e da unidade de seus povos. Nessa idealização, a Formação Superior Indígena tem contribuído por valorizar essas riquezas culturais observadas nesses povos, colaborando academicamente e cientificamente para que esses diferentes profissionais em suas comunidades tratem de suas peculiaridades e diversidades culturais de maneira altruísta, integral e relevante, provocando o autoconhecimento e o retorno às origens culturais de onde esses indivíduos foram criados. Tal posicionamento ainda se propaga na comunidade local, valorizando seus conceitos e autopercepções indentitárias tão necessárias.

Cada vez mais os povos indígenas no Brasil buscam o reconhecimento de suas especificidades culturais que implicam em modificações não homogeneizadas dentro de formações interculturais especificadas. A análise e abordagem nos centros de estudos, sejam acadêmicos, sejam de Formação Superior, emerge uma perspectiva que contribui brilhantemente na sociedade local, aumentando a percepção de como cada vez mais, os núcleos sociais diversificados em seus pluralismos culturais; tornam-se ricos em suas peculiaridades culturais e seus conhecimentos multiculturalizados.

\subsection{Considerações sobre a política brasileira de formação superior indígena}

A política nacional com viés de Formação Superior, por meio de diferenciados conteúdos em território nacional, baseada no Referencial Curricular Nacional para as Escolas Indígenas - RCNEI. São diretrizes e orientações fundamentais para o trabalho com diferentes áreas do saber com propósito de formação nas escolas indígenas inseridas no Ensino Fundamental. Conforme prevê o Ministério da Educação, o RCNEI tem por finalidade oferecer bases orientadoras para o desenvolvimento de programas de educação escolar no 
contexto indígena, atendendo aos seus próprios interesses e peculiaridades. No entanto, este contexto, não pode, ou não deveria afastar-se de princípios como pluralidade cultural e equivalência de tratamento para os cidadãos como um todo. Tal posicionamento também deve ser fundamento para a elaboração de material didático para a formação de professores indígenas (BRASIL, 1998).

Paladino (2012) constata hoje no Brasil a existência de 26 cursos de Licenciaturas Interculturais, funcionando junto às Universidades Públicas, todos financiados pelo Ministério da Educação, exclusivamente para a formação de professores, mas isso pode ser ampliado, contemplando até mesmo a Educação a Distância. Surgem, aos poucos, bacharelados específicos, como por exemplo, em Gestão Territorial Indígena, bem como Faculdades Interculturais. Outra forma que possibilita a presença de estudantes no ensino superior é propiciada por políticas de cotas, que se materializa em fomentar o ingresso por meio de reserva de vagas, bem como bônus que consiste em acréscimo de pontos nos processos seletivos e vagas suplementares em cursos regulares e convencionais.

Nesse movimento de descoberta, há uma maior valorização da própria cultura como algo que está posto dentro de um panorama de modificação construtiva de novos processos históricos ampliando a "percepção de que os direitos individuais e coletivos diversificados" são direitos históricos, cuja gênese está fecundada nas experiências vividas por um núcleo social através dos tempos (BOBBIO, 1992, p. 18).

Pode-se compreender que há um grande interesse dos povos indígenas pelo ensino superior, relacionando essa demanda com a aspiração coletiva de enfrentar as condições de vida e marginalização. A educação superior pode servir, portanto como:

ferramenta para promover suas próprias propostas de desenvolvimento, por meio do fortalecimento de seus conhecimentos originários, de suas instituições e do incremento de suas capacidades de negociação, pressão e intervenção dentro e fora de suas comunidades (BANIWA, 2010, p.8).

Conforme Baniwa (2010), a universidade está aliada à afirmação do indivíduo, partilhando da crença que há, no olhar estimado do outro, a possibilidade de construir ou reforçar a autoestima coletiva dos povos ameríndios, reforçando assim as suas identidades étnico-culturais.

Nas palavras de Fernandes (2008), atualmente, tem surgido uma grande necessidade de acesso aos professores indígenas à qualificação superior de suas formações acadêmicas, verificamos: 
É importante ressaltar a necessidade em formas específicas de ingresso para indígenas e, sobretudo, de estratégias para garantir a permanência dos mesmos no ensino superior, uma vez que somente possibilitar o ingresso, não é suficiente para garantir a formação. Dessa forma, pode-se afirmar que a atuação dos Núcleo Insikiran foi um avanço sem precedente. Prova disso é que em 2007 ingressaram 71 novos estudantes indígenas somente por meio de Processo de Seleção Específica na UFRR, sem contar os que entraram por processo regular (5 alunos), e nas faculdades particulares. [...] Há que se garantir a criação de políticas permanentes nessas instituições caso do Curso da Licenciatura Intercultural. Há também que se reforçar o segundo elemento deste processo, que hão de garantir a permanência dos estudantes nos cursos para que consigam concluí-los com êxito. Somente assim os estudantes poderão atender as suas comunidades e contribuir com a melhoria da qualidade de vida das mesmas (FERNANDES, 2008, p. 42).

Compreender as implicações necessárias às especificidades dos povos e suas culturas e trazer ao debate a desconstrução de um paradigma homogeneizante que cria uma falácia que todos seriam iguais. Seria um equívoco não levar em consideração que há diferentes características cognitivas e culturais estando desigualmente distribuídas (CANCLINI, 2004).

Respeitar essas individualidades é respeitar nosso próprio mundo. Nossa individualidade não teria existência se o outro não a criasse. A distância para compreender inicia o processo dialógico. Conhecer é reconhecer a presença do outro: a compreensão sempre é, em certa medida, dialógica (BAKTHIN, 1992).

Sobre isto, Silva (2011) destaca que a valorização da identidade tem forte relação sociológica e representativa, isto soma uma grande quantidade de elementos ricos nessas relações, podendo servir de recurso, ou viés transformador dos envolvidos. Essas representações somam contribuições culturais, experiências formativas e a construção de possibilidades para o exercício cidadão desses indivíduos. Hall (1999) define esses elementos presentes nessas interações sociais diversificadas e amplas, com fluidez cultural, pois estão em constante modificação, reestruturação e interação. Essas interações amoldam-se às necessidades nas quais esses indivíduos estão inseridos, vivendo suas histórias de vida.

Cavalcanti e César (2007), de igual modo, destacam que essa interação social evidencia-se por meio de identidades com amplas traduções e significações, como a exemplo das identidades culturais presentes nos povos indígenas de Roraima. À medida em que as instituições de Formação Superior valorizam essa necessidade de favorecer o acesso ao ambiente acadêmico por parte desses diferentes grupos sociais superam-se modelos equivocados e excludentes.

Xavier e Cortez (2003) ainda informam que existem uma enorme quantidade de influência nos modos culturais em diferentes instâncias e modos de pensamento humano, isso 
deve ser tido como uma grande oportunidade formativa para o conhecimento e para a conservação dessa cultura que faz parte da identidade do povo brasileiro.

A Formação Superior indígena abrange a necessidade de uma diversificada e ampla capacitação acadêmica aos professores indígenas que possibilite uma inserção em suas culturas de modo a defender, disseminar e possibilitar a propagação de uma identidade indígena mais plena e carregada de sentimento de cultura própria e preservação de tradições que permeiam longos processos históricos.

\subsection{A necessidade do reconhecimento de uma formação superior indígena e multicultural (a questão da etnicidade e identidade indígena diversificada)}

Conforme explica Freitas (2003), ser índio cristaliza-se no sentimento de pertencer a um determinado grupo étnico, num movimento, ao mesmo tempo, de exteriorizar ao mundo o que se é e internalizado no próprio indivíduo que se reconhece nessa condição, pois dentro dele está uma grande quantidade de relações reflexas de sua cultura e de sua identidade

Pode-se perceber assim, que os povos indígenas possuem demandas presentes nessa relação de interação com sua própria culturalidade, necessitando, desta forma, de um reconhecimento por parte dos ambientes acadêmicos de formação superior. Por meio dessa formação especificada, dentro de sua realidade local e adequada ao seu grupo de vivência cultural, esses indivíduos podem ter suas cidadanias reconhecidas e valorizadas, por sua própria origem.

Paredes (1996) ainda determina que a luta e reivindicações dos indígenas brasileiros, corresponde às suas necessidades de reconhecimento de:

diversidade linguística e cultural, [...] e reconhecimento de uma educação própria, bilíngue, intercultural, específica e diferenciada, conforme o que declara a Constituição Federal "são reconhecido aos índios sua organização social, costumes, línguas, crenças e tradições” (Art 231 CF/88) (PAREDES 1996, p. 13).

Paredes (1996) ainda destaca que essa formação deve ater-se à necessidade de uma adequação pedagógica à língua de alunos indígenas;

A existência e o direito a uma educação está fundamentada no reconhecimento da coexistência de duas ou mais populações (índios e não índios) dentro de um mesmo território, e portanto, de uma diversidade cultural e linguística; o que quer dizer que uma educação indígena tem que ser pelo menos intercultural e bilíngue. Só quando for assim, poderemos estar falando de uma educação própria dos índios, pois respeitará e valorizará a sua própria língua e a sua cultura. Quando isto acontecer, se estará reconhecendo e valorizando a identidade indígena (PAREDES 1996, p. 15). 
É de extrema importância compreender que os aspectos culturais e de pluridade étnica devem ser observados, quando da formação de professores para atuarem dentro da realidade educacional de povos indígenas. Etnicidade é essencialmente uma "forma de interação entre grupos operando no interior e contextos sociais comuns" (OLIVEIRA; BAINES, 2005, p.12). Os mesmos autores afirmam que a etnicidade abriga, em maior ou menor grau, sistemas de interação entre nacionalidade que, em termos estruturais, influenciam (falando isto em alta e determinante influência), à medida que somam diferentes contribuições em sistemas interétnicos diversificados (OLIVEIRA; BAINES, 2005).

Compreendendo este ponto, conforme os autores, isto significa que:

A natureza da identidade étnica não guarda homologia com a da cultura, ainda que ambas, mantenham estreita interação. A rigor, dos elementos ditos culturais, sempre estarão a serviço da identidade como sinais diacríticos, diferenciadores, planejados pelos indivíduos e grupos para marcar simbolicamente suas respectivas, especificidades (OLIVEIRA; BAINES, 2005, p. 11).

As histórias dos povos indígenas no Brasil, é uma história que sempre esteve atrelada às lutas pela terra, pela cultura e pelo reconhecimento de uma identidade indígena de amplo sentido e diferenciada. Paredes (1996) descreve a relevância da valorização multicultural que respeite a identidade de um povo quando diz:

\begin{abstract}
A história dos povos indígenas latino-americanos é a história da luta pela terra esta luta lhes permitirá a valorização da sua língua e da sua cultura, valorização que dará origem a uma nova luta, a luta por uma educação, por uma educação própria, na sua própria língua e que ensine aspectos da sua cultura. Neste sentido, a manutenção e a defesa da identidade de um povo passa pelo respeito a [...] sua mesma cultura, [...], pois sem ela se desequilibram e se desarticulam (PAREDES, 1996, p.14).
\end{abstract}

Assim, se evidencia uma atual necessidade de que professores indígenas tenham uma Formação Superior que lhes forneça essas considerações e aspectos, para tornar integral e integralizado os mais diversos saberes presentes em suas culturas. Essa complexidade de requisitos necessários e educacionais exige um alto "nível de formação e capacitação docente dos educadores, pela existência de características linguísticas, culturais, históricas, sociais, econômicas e políticas e particulares” (PAREDES, 1996, p.27).

Assim como, o descrito por Jovchelovitch (2003), que estabelece como condição sine qua non (sem a qual não pode existir) que toda a representação sociocultural humana depende diretamente das relações presentes nos pluralismos oriundos de suas próprias expressões sociológicas. 
Woodward (2000) destaca que diferentes culturas expressam-se por meio de diversificados de contextos simbólicos presentes em dois aspectos muito marcantes, o sociológico e o histórico. A realidade indígena é inerente a essas perspectivas, tamanha a sua amplitude. Sobre o mesmo entendimento, Minayo (1994) descreve que não há como se compreender as perspectivas sociais presentes em diferentes conjecturas vivenciadas nas identidades humanas, sem aprofundar as traduções e relações presentes nos contextos sociológicos de sua realidade.

Compreender uma Formação Superior indígena com qualidade e que leve em considerações contextos importantes como as etinicidades e multiculturalidades, surgem com um fator determinante de reconhecimento da cidadania indígena no Brasil, respeitando suas individualidades e realidades sociais diferenciadas:

A existência da condição intercultural da educação indígena, especialmente através da escola, garante o reconhecimento da cidadania dos índios brasileiros, pois, como os povos indígenas tem que reagir com a população nacional, na sua maioria nãoíndia, eles teriam acesso a aprofundar e desenvolver seus próprios saberes e conhecimentos, além dos conhecimentos e valores da comunidade nacional, que facilitem a melhor convivência e compreensão das duas realidades. Somente através de uma educação que garanta um reconhecimento e respeito das duas realidades, entendidas como diferentes, mas não irreconciliáveis, se estará garantindo uma educação que promova a cidadania dos índios, tanto local (como índios), como nacional (como brasileiros), sem perda das suas identidades [...] nesse sentido, precisa-se de professores de ótima qualidade, tanto em seus conhecimentos, como no domínio de aptidões de ensino, e com uma ideia e consciência do significado de interculturalidade. Portanto, não é suficiente contratar indígenas como professores, senão que se tem que contratar indígenas suficientemente capacitados como professores (PAREDES, 1996, p.16).

Poroloniczak (2002), escrevendo sobre como deve ser a formação intercultural e superior indígena, informa:

10. As escolas indígenas serão criativas, promovendo o fortalecimento das artes como formas de expressão de seus povos.

11. É garantido o uso das línguas indígenas e dos processos próprios de aprendizagem nas escolas indígenas.

12. As escolas indígenas deverão atuar junto às comunidades na defesa, conservação, preservação e proteção de seus territórios.

13. Nas escolas dos não-índios será corretamente tratada e veiculada a história e cultura dos povos indígenas brasileiros, a fim de acabar com os preconceitos e o racismo.

14. Os Municípios, os Estados e a União devem garantir a educação escolar específica às comunidades indígenas, reconhecendo oficialmente suas escolas indígenas de acordo com a Constituição Federal.

15. A União deverá garantir uma Coordenação Nacional de Educação Escolar indígena, interinstitucional, com participação paritária de representantes dos professores indígenas (POROLONICZAK et al, 2002, p.13). 
Permitir uma Formação Superior Indígena multicultural embasada em diferentes contextos étnicos possibilitaria identificar que o ser humano possui suas diversificadas realidades e individualidades, sendo que a vivência acadêmica também deve superar a hegemonia preconceituosa que isola o indivíduo, de modo a evidenciar a riqueza de construções históricas multifacetadas com específicas expressões de construção sociológicas e fluxos de tradições.

\subsection{A necessidade de um Curso de Formação Superior em Língua no Insikiran - UFRR}

Entre suas atribuições, o Insikiran detém a incumbência de viabilizar a formação acadêmica multicultural por meio das atividades administrativas e formativas presentes na UFRR, que conforme destaca Carvalho, Fernandes, e Repetto (2009) assume o interesse de permitir políticas públicas educacionais e atitudes institucionalizadas para atender os interesses dos povos indígenas em Roraima.

Cumpre destacar que o Insikiran, até o presente momento, tem ofertado à comunidade geral, em se tratando de cursos de Língua Indígena (Macuxi e Wapishana), apenas cursos de extensão, não havendo, por exemplo, um curso de formação de professores (graduação) com essa finalidade. Assim, o que se tem ensinado no Instituto Isikiran é originado da experiência de indígenas que se comunicam em Língua Indígena nas em suas comunidades de origem e, devido a esta experiência pessoal, deslocam-se até a cidade para ensinarem com ajuda de dicionários e alguns manuais já publicados, sobre essas línguas indígenas.

Sobre isto, Olveira (2003, p.39) esclarece que a Declaração dos Direitos Linguísticos, mais precisamente em seus artigos 46 e 23, háo a informação de que "toda comunidade linguística tem direito à preservação de seu patrimônio linguístico e cultural”.

De igual modo, Sílvio Coelho dos Santos, em sua obra intitulada "Educação e sociedades tribais" publicada na década de 1970 (SANTOS, 1975), esclarece que as instituições de ensino superior devem ofertar possibilidade de formação acadêmica voltada às necessidades de povos com constituição étnica, histórica e cultural altamente diversificadas, como a exemplo dos povos indígenas de Roraima.

Maher (2007), também tecendo comentários sobre a Formação Superior de professores que tratam sobre Língua Indígena, destaca que não há com se considerar diversidades culturais sem abranger possibilidades, aos povos indígenas, de conhecerem, entenderem e dominarem a língua de seus antepassados. Somente, desta forma, se poderia permitir a conservação e o resgate cultural tão necessários à esses indivíduos. 
Por meio dessas atitudes institucionais e pedagógicas, de acordo com o que afirma Soriano Ayala (2001) se assuumiria uma luta mais ampla contra a segregação, o isolamento e a deterioração da identidade cultural presente nos pluralismos culturais, tal qual o presente nos povos indígenas de Roraima efetivando contextos pedagógicos multiculturais que se adequem as demandas desses grupos.

\section{ANÁLISE}

Diferentes cidadanias geram diferentes demandas na sociedade. A Formação Superior indígena possui muitas perspectivas ainda a serem pensadas como estratégias de formação de profissionais que possam, de maneira efetiva, corresponder às realidades das comunidades indígenas em Roraima. Contudo, muito se tem feito, para de algum modo, criar oportunidades que favoreçam mecanismos multiculturais, sejam de didáticas formativas, sejam de acesso a conteúdos que integralizem estratégias de ensino inclusivas, aos alunos indígenas.

Tratando disto, adentrando os dados para a análise da realidade em estudo, foram obtidas algumas declarações de professores da UFRR por meio de aplicativo de rede social, a primeira, no dia 02 de maio de 2018 (MACHADO, 2018) e a segunda, no dia 25 de maio de 2018 (MAFRA, 2018), que foram transcritas de forma descritiva que, conforme destaca Manzini (2006) possibilita a tradução verbal adaptada de um determinado cenário em estudo.

Assim, por meio das declarações feitas declarações da professora Machado (2018) do Programa de Pós-graduação em nível de mestrado PPGL/UFRR, Dra. e do Professor de Língua Macuxi, Mafra (2018), ambos atuam também no Programa de Valorização das Línguas e Cultruras Macuxi e Wapichana. Também foram entrevistados 30 alunos do Curso de Gestão em Saúde, no intuito de aprofundar os objetivos da pesquisa. Com ajuda desses dados, foram evidenciados importantes relatos sobre a realidade pedagógica multicultural presente no Instituto Insikiran da UFRR.

Ao serem questionados sobre o que entendem como sendo Formação Superior Multicultural, a Machado (2018) informou que considera esta, como sendo a formação que comunica-se com múltiplas culturas convivendo e trocando experiências de formação. Já o Professor de Mafra (2018), de Língua Macuxi, destacou que se trata de um perfil de Formação Superior que entende a realidade das diferentes comunidades indígenas de Roraima, compreendendo como as suas vivências participam dessa realidade no ambiente da faculdade. 
Fleuri (2001) relaciona que a perspectiva multicultural assume uma multiplicidade de diferentes práticas culturais que se encontram gerando imbricações que se confrontam entre diferentes sujeitos, ampliando significações e trocas culturais coletivas. Isto pode favorecer diferentes aprendizagens e diferentes contatos culturais no ambiente acadêmico.

Ao segundo questionamento, os dois professores entrevistados foram perguntados sobre como a Formação Superior Multicultural pode beneficiar acadêmicos de Roraima. A esta pergunta Machado (2018), informou que o multiculturalismo pode favorecer o aluno no sentido deste compreender que não é só o ponto de vista dele que deve participar do ambiente acadêmico, mas de outras culturas também, de outras visões de mundo, bem como outras formas de vivenciar culturas diferentes.

Mafra (2018), relaciona essa realidade com o fato de que o multiculturalismo pode proporcionar uma visão mais ampla da vida do indígena, das diferentes comunidades e como essa visão está em contato com os conteúdos de sua formação acadêmica, a exemplo, da Língua Indígena que pode ajudar o aluno a compreender a realidade de seus amigos e parentes falantes dessas línguas que antes, este não compreendia, ou compreendia apenas um pouco.

Quando indagados se a Formação Superior Multicultural disponibilizada pela UFRR no Insikiran tem beneficiado os mais diferentes povos indígenas em Roraima, Machado (2018) pontuou que tem visto uma boa atuação da instituição em nesse sentido. O Insikiran permitido um ambiente de formação com amplos recursos para que diferentes povos e diferentes culturas troquem e adquiram conhecimentos, bem como, possam manifestar de modo muito amplo suas realidades. Ainda assim, segundo apontou a Coordenadora, deve ser levado em consideração que há muito ainda a ser feito, pois as didáticas formativas nem sempre tem se efetivado na vida do aluno, pois estão não abarcam alguns povos específicos em seu acesso, como no caso do Ingarikó e Yanomamis, que nem sempre conseguem compreender o português (MACHADO, 2018).

Mafra (2018) compreende que os povos indígenas têm tido muitos benefícios com essa formação diferenciada presente na UFRR e no Insikiran, pois por meio dela os alunos indígenas podem obter formação acadêmica necessária para atuarem com qualidade nas suas comunidades de origem.

Sobre isto, Mac Laren (2000) afirma que a Formação Superior multicultural soma-se ao papel democrático das universidades correspondendo a um incentivo acadêmico para contribuição de demandas presentes nas diferentes comunidades indígenas espalhadas pelo Brasil, vez que esses Cursos de Formação Superior adequam-se tanto em propostas formativas como em grade curricular às realidades e demandas presentes nas comunidades de 
origem desses alunos. Essa formação possibilita uma emancipação desses povos, tornando-os detentores de oportunidades iguais as que indivíduos não índios têm acesso.

Ao serem questionados se a UFRR tem disponibilizado Formação Superior multicultural suficiente aos diversos povos indígenas em Roraima e se haveria alguma coisa a ser melhorado neste contexto, Machado (2018) observa que a UFRR tem feito muito pela interação e troca cultural entre os diferentes povos indígenas de Roraima, no entanto nem tudo está sendo valorizado, uma vez que há ainda perspectivas mais específicas por exemplo no caso de alunos yanomamis. No caso destes alunos, o aprendizado deveria ser mediado por um intérprete, o que ainda não é disponibilizado no Insikiran e isso pode ocasionar dificuldades no acesso ao conhecimento formativo na faculdade. Machado (2018) ainda considerou que falta espaços mais amplos para diferentes culturas de fato vez que nem sempre se realizam trocas culturais favoráveis à amplas experiências de formação.

Mafra (2018) pontuou que a Formação Superior multicultural disponibilizada pela UFRR e o Insikiran tem sido suficiente uma vez que entende melhor a realidade do aluno indígena de sua comunidade, sendo que essas realidades ainda podem melhorar, pois algumas etnias ainda encontram a barreira presente na língua nesse processo de aprendizagem.

Essas informações ajudam a compreender a realidade dos alunos indígenas em Roraima. Também favorecem uma melhor reflexão sobre a Formação Superior Indígena e Muticultural e questões reflexas sobre etnicidade e identidade indígena. Ajudou ainda a esclarecer melhor sobre a necessidade de considerar os aspectos presentes no contexto das línguas indígenas de Roraima para um efetivo exercício pedagógico multicultural.

Segundo Machado (2002), as Instituições de Formação Superior no Brasil devem assumir um papel inclusivo de favorecer o exercício cultural em diferentes perspectivas, assumindo esse papel livre de preconceitos e modelos equivocados ou ainda homogeneizantes.

Repetto (2008), na obra Propostas Educativas em Cidadania Intercultural também informa que a formação multicultural é aquele que se personifica numa sociedade plural, onde a cidadania deixe de ser um conceito abstrato e homogeneizante. Essa cidadania assume um papel mais abrangente, construindo uma sociedade que respeite o direito das pessoas e das coletividades. E nessa perspectiva, o Insikiran tem somado esforços para promover essa inclusão acadêmica, valorizando identidades culturais presentes na formação dos povos de Roraima.

Quando os entrevistados foram indagados se seria importante a disponibilidade de um curso de Formação Superior em Língua Macuxi, na modalidade a distância que formasse 
professores nas localidades mais distantes da capital de Roraima (Boa Vista), que pudesse ser disponibilizado pelo Insikiran/UFRR.

Machado (2018) destacou que seria de grande valia, pois, nem sempre os alunos conseguem chegar a capital para obterem uma formação acadêmica. Destacou ainda que ainda não há nenhum curso de formação de professores em uma das várias línguas indígenas de Roraima, sendo este um tema que deve ser considerado pela Universidade Federal de Roraima, visto que traria muitos benefícios para os seus participantes.

Mafra (2018) relatou que os professores que lecionam no Insikiran em Cursos de Língua Indígena (Macuxi e Wapichana) são falantes da língua sem uma formação acadêmica nessa área para esta finalidade. São moradores da comunidade indígenas que aprenderam com seus avós, seus pais, seus parentes de convívio comum e desenvolveram o domínio da língua. Destacou que seria muito interessante uma formação acadêmica neste sentido, pois ajudaria a criar profissionais gabaritados para atuar em sala de aula. $\mathrm{O}$ professor ainda frisou que isso serviria para revitalizar a cultura dos povos indígenas de Roraima evitando que esse conhecimento dessas línguas se perdesse com o tempo.

Sobre isto, Freitas (2003) considera que à medida que as Instituições acadêmicas assumem esse papel criam-se mecanismos para garantia de direitos presentes no resguardo do exercício cultural dos povos e minorias historicamente constituídos por meio de diferentes processos e diversificados contextos culturais, cedendo ao apelo do outro de suas realidades e visões de mundo.

Em um segundo momento da coleta de dados, fram aplicados 21 questionários a 21 alunos da turma de Gestão em Saúde Coletiva 2019.1 do Insikiran/UFRR. Eles assinaram o Termo de Consentimento Livre e Esclarecido (TCLE). Nos questionários foram incluídas diversas questões, recortamos aqui o que interessa diretamente a discussão proposta neste texto. Adiante, compreenderemos um pouco melhor essas informações: foi indicado por 01 dos entrevistados o motivo gerador de uma demanda de alunos indígenas por um Curso de formação de professores de língua indígena a questão de haver seletivos que contratam professores biblíngues.

Um dos alunos Almeida (2019) disse que: "na maioria das vezes é inviável para o aluno indígena, sair de sua região" disse ainda que são motivos que impedem o aluno de vir a capital obter uma formação superior " [...] transporte e as condições das estradas em tempos de chuva". Esta fala revela como os alunos mesmo enfrentando uma série de dificuldades se esforçam para estudar. 
Gráfico 1 - A importância, para os alunos, da disponibilidade de um Curso de Formação Superior em pelo menos uma das línguas indígenas de Roraima a ser ofertado pela UFRR)

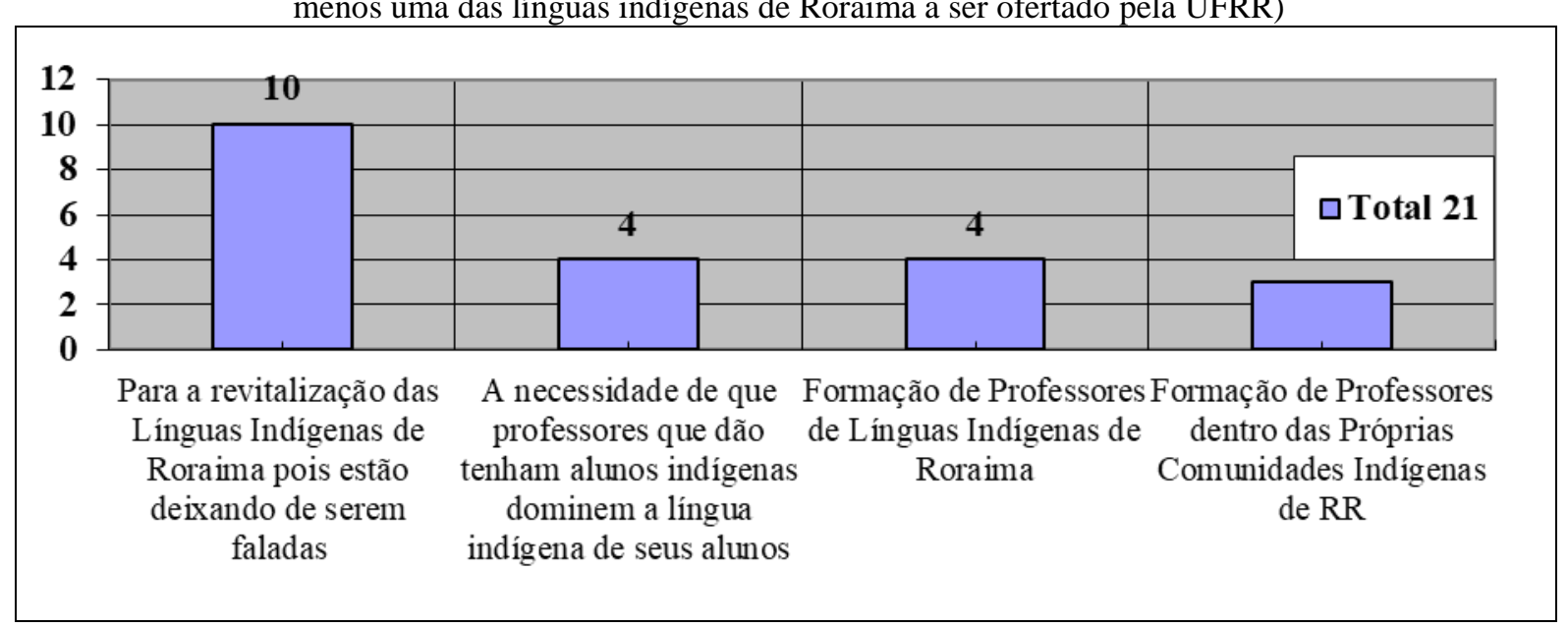

Fonte: Elaboração do Autor (2019).

Na Questão acima os alunos deveriam citar um motivo pelo qual seria importante para os alunos indígenas e não indígenas da UFRR, a disponibilidade de um Curso de Formação Superior em pelo menos uma das Línguas Indígenas de Roraima. Se não houver um motivo, descreva porque não seria importante. Entre as 21 respostas à questão, foram obtidas quatro perspectivas de respostas:

1) Para a revitalização das Línguas Indígenas de Roraima, pois estão deixando de serem faladas - indicado por 10 dos entrevistados como sendo um motivo pelo qual seria importante para os alunos da UFRR, a disponibilidade de um curso de Formação Superior em Língua Indígena. Este quantitativo representa $47,61 \%$ dos que responderam ao questionamento acima.

2) A necessidade de que professores que dão aula nas escolas indígenas tenham alunos indígenas dominem a língua indígena de seus alunos - indicado por 04 dos entrevistados como sendo um motivo pelo qual seria importante para os alunos da UFRR, a disponibilidade de um curso de Formação Superior em Língua Indígena. Este quantitativo representa $19,04 \%$ dos que responderam ao questionamento acima.

3) Formação de Professores de Línguas Indígenas de Roraima - indicado por 04 dos entrevistados como sendo um motivo pelo qual seria importante para os alunos da UFRR, a disponibilidade de um curso de Formação Superior em Língua Indígena. Este quantitativo representa $19,04 \%$ dos que responderam ao questionamento acima.

Bernardi (2011) define que no atual momento histórico é necessária a formação de professores indígenas, visando a continuidade de suas culturas e reafirmação da construção dos elementos que as lideranças indígenas considerem importantes. Permitir esse 
protagonismo e garantir um tratamento equitativo no exercício da cidadania desses indivíduos.

Scriptori (2004) esclarece que cada vez mais as universidades contemporâneas devem identificar possibilidade e contextos que construam sociedades do conhecimento. Isto envolve alto grau de capacitação formativa e um melhor gerenciamento de políticas administrativas que somam esforços para acompanhar o desenvolvimento tecnológico da realidade atual.

Entre as perspectivas as quais a política administrativa e acadêmica da UFRR se fundamenta, podemos citar a Identidade, Multiculturalismo, Hibridismo Cultural e Interculturalismo. Assumindo esse posicionamento, já existe a oferta de cursos como Língua Portuguesa, Língua Francesa, Língua Inglesa e Língua Espanhola. Entretanto, não há, mesmo sob o contexto de uma grande quantidade de etnias indígenas, nenhum curso dentre as línguas indígenas de Roraima. Soma-se a esta constatação o fato de que são pouquíssimos estudos que tecem comentários e observações sobre esse contexto e panorama.

Fica evidenciado nesse momento, no que diz respeito a esta abordagem e estudo, que há um interesse por um curso de Formação Superior em Língua Indígena Macuxi, conforme o dito pelos alunos do Instituto Insikiran/UFRR e professores entrevistados.

Ainda deve ser considerado que isso se trata de uma questão de autonomia de direitos desses alunos e, não só deles, mas de todos aqueles que identificam nessas culturas originárias da região Norte, algo a ser considerado e identificado como um elemento de diversidade cultural.

\section{Considerações Finais}

O multiculturalismo hoje surge como uma grande oportunidade de trocas culturais. Isso acontece em diferentes realidades no exercício de interação social dos indivíduos nas suas vivências diárias. As instituições de formação superior no Brasil também participam deste contexto. Roraima possui uma formação cultural ampla com diferentes povos indígenas que atuam neste cenário de maneira direta, constante. A Universidade Federal de Roraima tem servido como um celeiro de formação de profissionais de alto desempenho no mercado local, disponibilizando seus acadêmicos, tanto indígenas como não indígenas oportunidades equitativas de conhecimento e capacitação técnica para o mercado de trabalho. Têm também oportunidade expressões culturais, trocas de experiências que têm, pouco a pouco desmistificado conceitos, reelaborado oportunidades de conhecimento que podem servir como instrumentos de valorização cultural dos povos originários locais. 
A Formação Superior Indígena multicultural é uma forma de reconhecer direitos destes povos com grande diversidade cultural, baseada em suas formações étnicas diferenciadas, favorecendo que lá, dentro da realidade das comunidades indígenas de Roraima, possa ser fomentadas oportunidades de conhecimento de interação e desenvolvimento destas comunidades com profissionais que vieram até a Universidade Federal em busca de realizarem sonhos que lhe permitam ter ferramentas suficientes para seu exercício cidadão.

Assim sendo, esses ambientes de formação acadêmica devem compreender que mesmo abrangendo contextos de identidade cultural diversificada, formação étnica diferenciada, como as presentes nos povos indígenas de Roraima e na realidade dos alunos que tem tido acesso à Formação Acadêmica multicultural na UFRR por meio do Insikiran, ainda não há um Curso de Formação Superior em Língua Macuxi que possa formar professores nessa modalidade de conhecimento.

Notadamente, como o observado nos relatos dos professores do Instituo Insikiran, muito se tem feito para valorizar o acesso desses indivíduos à formação superior. No entanto, ainda está presente e latente necessidade de que se amplie horizontes formativos às necessidades das diferentes demandas daqueles alunos sejam eles indígenas ou não, que queiram obter uma formação superior em Língua Indígena. Viabilizar essa oportunidade à formação superior resolveria satisfatoriamente problemas de acesso de alunos que moram em comunidades mais distantes que nem sempre conseguem transporte para vir a cidade ou local para se hospedarem a fim de cumprir essa etapa em suas formações de conhecimento.

Compreender que essa demanda cria a oportunidade de se pensar um curso na modalidade a distância em suas comunidades de origem pode favorecer a formação de profissionais que atuem diretamente no seu contexto social, enobrecendo o seu papel na revitalização cultural de seu povo. Esta abordagem de pesquisa e os elementos teóricos destacados nessa perspectiva de análise permitem descrever esses elementos. As falas dos alunos identificam dificuldades que poderiam ser superadas por meio de uma Formação Superior Indígena em uma das Línguas Indígenas de Roraima.

A medida que trazemos ao conhecimento essas questões, possibilitamos uma melhor reflexão sobre esse assunto, percebemos, um dos autores como indígena do povo Macuxi, que a pesquisa científica pode dar voz e vez para esses indivíduos que por vezes, passam esquecidos das políticas acadêmicas que ficam, em muitos casos, limitadas a apenas alguns grupos. 


\section{Referências}

BAKHTIN, M. Estética da criação verbal. São Paulo: Martins Fontes, 1992, p.55.

BANIWA, G. Territórios etnoeducacionais: um novo paradigma na política educacional brasileira. In: CONAE, 2010, Brasília. Anais. Brasília, DF: MEC, 2010.

BOBBIO, N. A Era dos Direitos. Rio de Janeiro: Campus, 1992.

BRASIL, Ministério da Educação. Referencial Curricular Nacional para as Escolas Indígenas. Brasília: MEC, 1998.

BERNARDI, Lucí T. M. dos Santos. Formação continuada em matemática do professor indígena Kaingang: enfrentamentos na busca de um projeto educativo. Tese (Doutorado) Universidade Federal de Santa Catarina, 2011. Disponível em: $<$ https://repositorio.ufsc.br/handle/123456789/95735>. Acesso em: 01 de mai. de 2019.

CANCLINI, N. G., Diferentes, desiguales y desconectados: mapas de la interculturalidad. Buenos Aires: Gedisa, 2004.

CARVALHO, F., FERNANDES, M. L., REPETTO, M. Acesso e permanência de indígenas ao ensino superior: O Programa E'ma Pia, UFRR. Boa Vista: Editora da UFRR, 2009.

CAVALCANTI, M. C.; CÉSAR A. L. Do singular para o multifacetado: o conceito de língua como caleidoscópio. 2007.

FERNANDES, M. L. Indígenas no ensino superior: vagas específicas na UFRR. In: REPETTO, M.; FERNANDES, M. L.; NEVES, L. (Org.). Universidade inconclusa: os desafios da desigualdade. Boa Vista: Editora UFRR, 2008.

FLEURI, R. M. Intercultura: estudos emergentes. Ijuí. Ed. Unijuí-RS, 2001.

FREITAS, D. B. A. P. Escola Makuxi: identidades em construção. (Tese de Doutorado). Campinas: Unicamp, 2003.

GOMES, N. L.; SILVA, P. B. G. Experiências étnico-culturais para formação de professores. Belo Horizonte: Autêntica, $2^{\mathrm{a}}$ ed., 152 p.

HALL, S. A identidade cultural na pós-modernidade. Rio de Janeiro: DP\&A, 1999.

JOVCHELOVITCH, S. Vivendo a vida com os outros: intersubjetividade, espaço público e representações sociais. In: GUARESCHI, P.; JOVCHELOVITH, S. (Orgs.). Textos em representações sociais. Petrópolis: Vozes, 2003. p. 63-85.

MACHADO, A. Entrevista concedida por meio de aplicativo de rede social em 02 de maio de 2018. Boa Vista, 2018. 
MACHADO, C. G. Multiculturalismo: muito além da riqueza e da diferença. Rio de Janeiro: DP\&A, 2002.

MAFRA, C. W. Entrevista concedida por meio de aplicativo de rede social em 25 de maio de 2018. Boa Vista, 2018.

MAHER, T., M. Do casulo ao movimento: a suspensão das certezas na educação bilíngüe e intercultural. In: CAVALCANTI, M.; BORTONI-RICARDO, S. M. (Orgs.). Transculturalidade, linguagem e educação. Campinas, SP: Mercado de Letras, 2007. p. 67-94.

MANZINI, E. J. Considerações sobre a entrevista para a pesquisa social em educação especial: um estudo sobre análise de dados. In: JESUS, D. M.; BAPTISTA, C. R.; VICTOR, S. L. Pesquisa e educação especial: mapeando produções. Vitória: UFES, 2006, p. 361-386.

McLAREN, P. Multiculturalismo revolucionário: pedagogia do dissenso para o novo milênio. 2. ed. Porto Alegre: Artmed, 2000.

MELIÁ, B. Educação indígena na escola. São Paulo, Caderno CEDES, 1999, p. 01.

MINAYO, M. C. S. O conceito de representações sociais dentro da sociologia clássica. In: JOVCHELOVITCH, S. \& GUARESCHI, P. (orgs.), Textos em representações sociais. Petrópolis, Vozes.

OLIVEIRA, R. C.; BAINES, S. G. Nacionalidade e etnicidade em fronteiras. Brasília: Editora Universidade de Brasília, 2005, p. 11-17.

OLIVEIRA, G. M. Declaração Universal dos Direitos Linguísticos: novas perspectivas em políticas linguísticas. Campinas: Mercado de Letras, Associação de Leitura do Brasil; Florianópolis: IPOL, 2003.

SANTOS, S. C. Educação e sociedades tribais. Porto Alegre: Movimento, 1975.

SORIANO A., E. (coord) Identidad cultural y ciudadanía intercultural: su contexto educativo. Editorial La Muralla, S.A. $1^{\text {a }}$ ed., $1^{\text {a }}$ imp. Madrid, 2001.

PALADINO, M. Educación escolar indígena: investigaciones antropológicas en Brasil y Argentina. Buenos Aires: Antropofagia: 2012, pp. 279-295.

PAREDES, J. B. B. Educação indígena e identidade. In: ASSIS, Eneida (Org.). Educação Indígena na Amazônia: Experiências e Perspectivas. Belém: Associação de Universidades Amazônicas, Universidade Federal do Pará, 1996.

POROLONICZAK, J. A.; MARQUES, D. P. C.; BAR, E. C.; NOGUEIRA, E. G. A formação dos Professores Indígenas no Paraná: uma questão a ser resolvida. In: Seminário e Políticas Sociais no Brasil, 2002, Cascavel - PR.

REPETTO, M., et al. Propostas em cidadania intercultural. Boa Vista: Editora UFRR, 2008, p.19. 
SCRIPTORI, C. C. (org.) Universidade e Conhecimento: desafios e perspectivas no âmbito da docência, pesquisa e gestão. Campinas, SP: Mercado das Letras, 2004. p. 49 - 63. (Coleção Educação e Psicologia em Debate).

SILVA, T. T. Identidade e diferença. Organizado por Tomaz Tadeu da Silva. Rio de Janeiro: Editora Vozes, 2011.

TUBINO, F. Ciudadanías Complejas y Diversidad Cultural. In: N. Vigil \& R. Zariquiey (editores). Ciudadanías Inconclusas. El ejercicio de los derechos sociedades asimétricas. GTZ - PUCP. Lima, 2003. p. 167-191.

WOODWARD, K. Identidade e diferença: uma introdução teórica e conceitual, in T. T. da Silva (org.J), Identidade e diferença: a perspectiva dos estudos culturais. Petrópolis, Vozes, 2000.

XAVIER, A. C.; CORTEZ, S. (orgs.). Conversas com Linguistas: Virtudes e controvérsias da linguística. São Paulo: Parábola Editorial, 2003, 200 p. 